\title{
Development of a direct quantitative detection method for Meloidogyne incognita and M. hapla in andosol and analysis of relationship between the initial population of Meloidogyne spp. and yield of eggplant in an andosol
}

\author{
Takayoshi Watanabe ${ }^{1,3}$, Hiroaki Masumura' ${ }^{1}$, Yuzo Kioka ${ }^{1}$, Katsunori Noguchi², $^{2}$ \\ Yu Yu Min ${ }^{3,4}$, Risa Murakami ${ }^{3}$ and Koki Toyota ${ }^{3}$
}

\begin{abstract}
A real-time PCR-based detection method was developed for the root-knot nematodes (RKNs) M eloidogyne incognita and $\mathrm{M}$. hapla in andosol. Different numbers of second-stage juveniles (J2) were artificially added into $20 \mathrm{~g}$ of soil not containing $M$. hapla and $M$. incognita and then DNA was extracted from the soils. There were significant correlations ( $r^{2}=0.8857, P<0.05$ in $\mathrm{M}$. incognita and $r^{2}=0.9978, P<0.01$ in $M$. hapla) between the threshold cycle (Ct) values and the number of nematodes added. Next, soils were collected at transplanting time from different sites (12 plots) in a field naturally infested with $M$. incognita and $M$. hapla to measure the initial population densities. RK Ns were distributed heterogeneously in the field: the initial population ranged from 0 to $24 \mathrm{~J} 2 / 20 \mathrm{~g}$ soil with the Baermann method, while that of $M$. incognita and $M$. hapla from 0.6 to $713 \mathrm{~J} 2$ equivalent (J2eq)/20 g soil and from 0.0 to $115 \mathrm{~J} 2 \mathrm{eq} / 20 \mathrm{~g}$ soil, respectively, with the real-time PCR method. The yield was determined by the sum of commercial sized eggplants harvested for 3 months of the cultivation period. The yield decreased in the plots with an initial population of RKNs more than $2 / 2 / 20 \mathrm{~g}$ soil with the Baermann method. In real-time PCR, the yields were low in the plots with the sum of initial M . incognita and $M$. hapla more than $128 \mathrm{~J} 2 \mathrm{eq} / 20 \mathrm{~g}$ soil. The present study established a quantification method with real-time PCR for M. incognita and M. hapla in andosol and evaluated the relationship between the initial population of M eloidogynespp. and the yield of eggplant. Nematol. Res. 43(2), 21-29 (2013)
\end{abstract}

Key word: Ct value, gall index, real-time PCR, root-knot nematode

\section{INTRODUCTION}

Root-knot nematodes (RKNs), M eloidogyne spp., cause significant losses of yield and quality in many crops all over the world, and the annual global losses have been estimated as US\$100 billion worldwide (Oka et al., 2000). There are four common species of RKN in the tropical and temperate areas: $M$. incognita, $M$. hapla, $M$. arenaria and M. javanica (M oens et al., 2009). A mong them, M . incognita and $M$. hapla are distributed widely in Japan, and cause damage to cash crops, fruit and root vegetables, such as cucumber, tomato, eggplant and sweet potato in Japan (Ichinohe, 1992).

The species of RKNs are separated from each other on the basis of the morphology of perineal pattern, stylet knob

${ }^{1}$ T sukuba Research Institute, Katakura Chikkarin Co L td , 5-5511 Namiki, T suchiura, Ibaraki, 300-0061, Japan.

${ }^{2}$ Katakura Chikkarin Co., Ltd., 1-13-5 Kudankita, Chiyoda, T okyo, 1020073, Japan.

${ }^{3}$ Graduate School of Bio-A pplications and Systems Engineering, Tokyo University of A griculture and Technology, 2-24-16 Nakacho, Koganei, Tokyo, 184-8588, Japan.

${ }^{4}$ Presently at Plant Pathology Department, Y ezin A gricultural University, Pinmanar, Myanmar. shape, and the length of stylet and dorsal gland orifice (Moens et al., 2009). However, it is difficult to identify species of RKNs with traditional techniques, and the identification of RKNs needs mature skills and a long time even for specialists. Thus, an alternative identification method is required. New identification methods of RKNs have been developed with some enzymes, such as esterase and malate dehydrogenase, and with DNA -based methods (Blok et al., 2009). The rapid development of DNA technology has been a breakthrough for overcoming the weak points of traditional identification methods (A tkins et al., 2005; Berry et al., 2007). Since Madani et al. (2005) reported real-time PCR specific primers for quantitative purposes of the potato cyst nematode Globodera pallida and the sugarbeet cyst nematode Heterodera schachtii, many specific primers have been designed for different plant-parasitic nematodes such as Bursaphelenchus xylophilus (Leal et al., 2007), Pratylenchus penetrans (Sato et al., 2007), M. incognita and G. rostochiensis (T oyota et al., 2008), M. javanica, P. zeae and Xiphinema elongatum (Berry et al., 2008), H. glycines (Goto et al., 2009) and $P$. thornei ( $Y$ an et al., 2012). However, no specific primers have been developed for $M$. hapla until now. 
Andosol is the major soil type in agricultural land in Japan and the most serious damage is caused by RKNs in this soil type (T akakura, 1984). Chemical control with fumigant or non-fumigant types of nematicides is frequently used, as an insurance against nematode damage, without a survey of plant-parasitic nematodes in fields. In almost all eggplant-producing areas of the country, nematicides are routinely used for the prevention of yield losses caused by RKNs (Hagiya, 1992). To avoid such an insurance-like application of nematicides, information about the economic threshold level is essential. Economic threshold levels have been developed using the Baermann method for M eloidogyne spp. in carrot (Sano, 1988), burdock (Y amada, 1992), spinach (Di Vito et al., 2004), potato (V ovlas et al., 2005), carrot (Gugino et al., 2006), eggplant (Schomaker and Been, 2006), celery (V ovlas et al., 2008), and cucumber and tomato (Plant protection station, 2011). However, these economic threshold levels may be underestimated and variable. The extraction efficiency of nematodes from soil using the Baermann method is estimated at about $50 \%$, and the method fails to extract eggs and dormant forms of nematodes (Ingham, 1994). Indeed, the Baermann method extracted only $30 \%$ of plant-parasitic nematodes recovered by the double-layer centrifugation method which extracts passive nematodes in soil as well as active nematodes (McSorley and Frederick, 2004). In addition, Den Nijs and $V$ an Den Berg (2013) revealed that the variance of M eloidogyne counts was the highest for the Baermann method, and concluded that the Baermann method is not advisable for survey purposes. A $n$ alternative quantification method with real-time PCR has been developed that enables quantifying all forms of nematodes (Goto et al., 2009; M in et al., 2011). In fact, M. incognita was detected with the real-time PCR method in soils which $M$. incognita could not be detected with the Baermann method ( $M$ in et al., 2012), suggesting economic threshold levels should be evaluated based on the nematode populations determined with real-time PCR. A ccording to our previous reports, calibration curves for estimating the density of a target nematode in soil differed depending on the type of soils used (Sato et al., 2010), but were similar within a single soil type, andosols (Goto et al., 2010). Min et al. (2011) used sandy soils for quantifying $M$. incognita, but no calibration curve was developed for andosols, the major soil type in Japan, at present.

The objectives of this study were to develop a rapid quantification method using real-time PCR for M . incognita and $M$. hapla in an andosol and to evaluate the relationship between the initial population of M eloidogyne spp. and the yield of eggplant in an andosol.

\section{MATERIALS AND METHODS}

Soil and nematode:

A ndosol without M eloidogyne spp. was collected from fields in Tokyo M etropolis, Japan, and used to make a calibration curve. The absence of $M$ eloidogyne spp. was confirmed by the Baermann method and the real-time PCR method, as described below. Nematodes were purchased from the NIAS (National Institute of A grobiological Sciences) Genebank in Japan.

\section{Primers:}

Specific primers for $M$. hapla [M h-f (5'-A TGTT GGTA CGCA GCGATTT GTA -3') - M h-r (5'-CA GCGGGT GAT CTC GACT GA - $\left.3^{\prime}\right)$ ] were designed based on the ITS1 sequences of M. hapla (A Y 268108), M. incognita (A B 053484) and M. arenaria (A F 077086) (T able 1). Specific primers for $M$. incognita used in this study were RKNf (5'-GCT GGT GT CT A A GT GT T GCT GA T A C-3'] - RKNr [5'-GA GCCT A GT GA T CCA CCGA TA A G-3'] reported by Toyota et al. (2008) (T able 1 ).

Primer specificity was evaluated using $M$. hapla and $M$. incognita with real-time PCR. DNA was extracted from individual J2s, according to the method of Iwahori et al. (2000) with slight modifications. A nematode was put into a drop of water on a glass slide, air-dried and cut with a sterile needle under a microscope. Then, $10 \mu$ of lysis buffer (10 $\mathrm{mM}$ tris(hydroxymethyl)aminomethane-HCl buffer (T ris$\mathrm{HCl}$ ), pH 8.0, $1 \mathrm{mM}$ ethylenediaminetetraacetic acid (EDT A ), 1\% IGEPA L CA -630, $100 \mu \mathrm{g} / \mathrm{ml}$ proteinase K) was added to the nematode. The buffer with the nematode was transferred into a $200 \mu$ tube, frozen at $-85^{\circ} \mathrm{C}$ for $15 \mathrm{~min}$. A fter thawing, the sample was incubated at $65^{\circ} \mathrm{C}$ for $1 \mathrm{~h}$ to degrade the nematode's body and then at $98^{\circ} \mathrm{C}$ for $10 \mathrm{~min}$ to inactivate proteinase $\mathrm{K}$. This solution was used as a DNA template in real-time PCR described below.

Preparation of calibration curves:

Different numbers $(5,20,80$, and 500$)$ of $M$. incognita or M. hapla $\mathrm{J} 2$ were added to $20 \mathrm{~g}$ of the reference soil. Each infestation level was prepared in triplicate and DNA was extracted in duplicate using the method reported by $\mathrm{M}$ in et al. (2012). Soil specimens were air-dried at $60^{\circ} \mathrm{C}$ for one night, and each of the $20 \mathrm{~g}$ air-dried soil samples were pulverized in duplicate with a ball mill (Mixer Mill MM400, Retsch Co., Ltd., Haan, Germany) for 2 min. Soil $(0.5 \mathrm{~g})$ was put into a 2-ml tube with $0.75 \mathrm{~g}$ of zirconia beads $(0.1 \mathrm{~mm}$ in diameter) and $0.25 \mathrm{~g}$ of glass beads $(0.5 \mathrm{~mm}$ in diameter), and $1,000 \mu \mathrm{l}$ of lysis buffer $(0.5 \%$ sodium dodecyl sulfate (SDS), $10 \mathrm{mM}$ Tris- $\mathrm{HCl}, 50 \mathrm{mM}$ EDTA , pH 8.0) and $100 \mathrm{mg}$ 
Table 1. Comparison of sequences in the positions of the primers used in this study.

\begin{tabular}{|c|c|c|}
\hline M. hapla specific primers & Sequence in the position of forward primer $\left(5^{\prime}-3^{\prime}\right)$ & Sequence in the position of reverse primer $\left(5^{\prime}-3^{\prime}\right)$ \\
\hline M. hapla (AY 268108) & ATGTTGGTA-CGCAGCGATTTG---T------AA & CAG--CGGGTGATCTCGA----CTGA $^{-1}$ \\
\hline M. incognita (A B 053484) & $\cdot \mathrm{AAG}^{-} \cdot \mathrm{A} \cdot \mathrm{T}-\mathrm{TTTGTTT} \cdot \cdots \mathrm{CA}---\cdot-----\mathrm{GT}^{2,3}$ & $\cdots--$ \\
\hline M. arenaria (A F 077086) & $\cdot \mathrm{AAG}^{-} \cdot \mathrm{A}^{\mathrm{A}} \cdot \mathrm{T}-\mathrm{TTTGTTT} \cdot \cdots \mathrm{CA}^{---} \cdot------\mathrm{GT}$ & $\cdots-$ \\
\hline M. javanica (GQ395513) & $\cdots \cdot$ AATC $\cdot-----------\cdot \cdot \mathrm{A}^{----} \cdot-------\mathrm{T} \cdot$ & $\cdots \mathrm{GCA} \cdot \cdot \mathrm{A} \cdot \mathrm{C} \cdot \mathrm{A} \cdot \mathrm{CA} \cdot \cdot \mathrm{TATCT} \cdot \mathrm{TT}$ \\
\hline M. camelliae (JX 912885) & $\mathrm{T} \cdot \cdots \cdot \mathrm{CGT} \cdot \cdot \mathrm{TT} \cdot \mathrm{GA} \cdots \cdot \mathrm{A}^{---} \cdot \mathrm{GGCCGG} \cdot$ & $\cdots--\cdots \cdots C \cdot \cdot A \cdot$ \\
\hline M. graminis (JN241896) & $\cdot \mathrm{C} \cdot \cdot----_{-----} \mathrm{T} \cdot \cdots \cdot \mathrm{G}_{---} \cdot-----\cdot \cdot$ & $\cdots--$. \\
\hline M. graminicola (JN241866) & $\cdot$ AAA $\cdot \cdot \mathrm{T} \cdot \mathrm{T}-\mathrm{TATT} \cdot \mathrm{GTT} \cdots \cdot \mathrm{T}---\cdot------\cdot \mathrm{C}$ & - \\
\hline
\end{tabular}

\begin{tabular}{|c|c|c|}
\hline M. incognita specific primers & Sequence in the position of forward primer $\left(5^{\prime}-3^{\prime}\right)$ & Sequence in the position of reverse primer $\left(5^{\prime}-3^{\prime}\right)$ \\
\hline M. incognita (A B 053484) & GCT----GGTGTCT----------AAGTGTT-GCTGATAC & GAGCC-----TAGTGATCCA-------CCGATAAG \\
\hline M. hapla (AY 268108) & 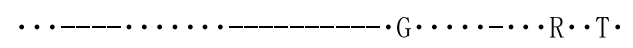 & 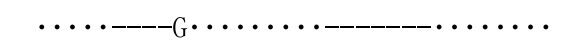 \\
\hline M. arenaria (A F 077086) & 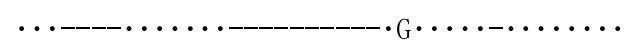 & $\cdots \cdots---G \cdot \cdots \cdot$ \\
\hline M. javanica (GQ395513) & $\cdots$ TTTC $\cdot \mathrm{A} \cdots \cdot \mathrm{TC}-------\mathrm{GC}^{-}-\cdots \cdot \mathrm{C} \cdot \mathrm{G}_{\mathrm{G}} \cdot \mathrm{GA} \cdot \mathrm{T}$ & $\cdots \cdots$ AATT $\cdots \cdots \cdots \cdot$ GCGAGAG $\cdots \cdots \cdot$ \\
\hline M. camelliae (JX 912885) & $\cdots----\mathrm{A} \cdots \mathrm{G} \cdot \cdot \mathrm{TGAACCGGGC} \cdot \cdot \mathrm{AA} \cdot \boldsymbol{C}-\cdot-\cdot \mathrm{A} \cdot \mathrm{C} \cdot \mathrm{A}$ & $\cdots \cdots----G \cdots$ \\
\hline M. graminis (JN241896) & 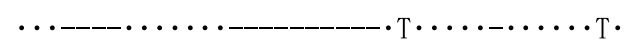 & 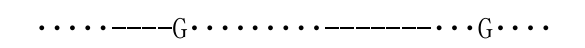 \\
\hline M. graminicola (JN241866) & $\mathrm{A} \cdot---\cdots \cdots \cdots \cdot-{ }^{---}{ }_{\mathrm{G}} \cdots \cdots \cdot \mathrm{T} \cdot$ & $\cdots_{A} \cdot \cdots--{ }_{-} \cdots \cdots \cdots \cdot--$ \\
\hline
\end{tabular}

The M. incognita primers were reported by Toyota et al. (2008).

${ }^{1}$ Numbers in parentheses after the species names indicates the accession number.

${ }^{2}$ Dots indicate the same base as above.

${ }^{3} \mathrm{Hyphens}$ indicate deletion of the corresponding base.

of skim milk were added. The soil was bead-beaten at 5,000 rpm for 1 min two times, followed by centrifugation $(13,000$ $\times \mathrm{g}$ for $5 \mathrm{~min}$ ). Then, $600 \mu \mathrm{l}$ of the supernatant was transferred to a new 2-ml tube, and $377 \mu \mathrm{l}$ of $5 \mathrm{M} \mathrm{NaCl}$ and $270 \mu \mathrm{l}$ of $10 \%$ hexadecyltrimethylammonium bromide (CTAB) were added to the tube. After $10 \mathrm{~min}$ incubation at $60^{\circ} \mathrm{C}$, $500 \mu \mathrm{l}$ of chloroform was added, and the tube was centrifuged at $15,000 \times \mathrm{g}$ for $20 \mathrm{~min}$. The supernatant $(1.1 \mathrm{ml})$ was transferred to a new 2-ml tube, $500 \mu \mathrm{l}$ of chloroform was added, and the tube was centrifuged at $15,000 \times \mathrm{g}$ for $20 \mathrm{~min}$. The supernatant $(1.0 \mathrm{ml})$ was transferred to a new 2-ml tube, then mixed with $600 \mu$ of $20 \%$ polyethylene glycol 8,000 (PEG) solution (20\% PEG, $1.6 \mathrm{mM} \mathrm{NaCl}$ ) and centrifuged at $15,000 \mathrm{rpm}$ for $20 \mathrm{~min}$ at $4^{\circ} \mathrm{C}$ to collect DNA as a pellet. The DNA pellet was washed with $1.0 \mathrm{ml}$ of $70 \%$ ethanol and centrifuged at $15,000 \mathrm{rpm}$ for $5 \mathrm{~min}$ at $4^{\circ} \mathrm{C}$ then dried using VC-15Sp (TAITEC Co., Ltd., Koshigaya, Japan) for $20 \mathrm{~min}$, and suspended in $100 \mu \mathrm{l}$ of TE buffer $(10 \mathrm{mM}$ Tris- $\mathrm{HCl}, 1 \mathrm{mM}$ EDTA, pH 8.0). The DNA was diluted 10fold and used as a template in real-time PCR.

\section{Real-time PCR protocol:}

Real-time PCR was performed in a StepOne Real time PCR System (Life Technologies Co., Carlsbad, CA) with a final volume of $10 \mu \mathrm{l}$ containing $2 \mu \mathrm{l}$ of 10 times diluted template DNA , $0.4 \mu$ of $10 \mu \mathrm{M}$ either primers for $\mathrm{M}$. hapla or primers for $M$. incognita and $5 \mu$ of $F$ ast SY BR $®$ Green Master Mix (Life Technologies) under the manufacturer's recommended conditions $\left(95^{\circ} \mathrm{C}\right.$ for $10 \mathrm{~s},\left(95^{\circ} \mathrm{C}\right.$ for $5 \mathrm{~s}$ and $60^{\circ} \mathrm{C}$ for $20 \mathrm{~s}$, at increasing and decreasing rates of $0.2^{\circ} \mathrm{C} / \mathrm{s}$ ) for 45 cycles). A negative control was also included using distilled water instead of a template DNA. Real-time PCR was done once per each DNA extract, since replicate samples showed almost identical values in real-time PCR.

\section{The Baermann method:}

Each soil sample was mixed well, and $20 \mathrm{~g}$ of the subsample was put in triplicate on two layers of tissue paper (Kimwiper $\circledast S-200$, NIPPON PAPER CRECIA Co., LTD., Tokyo, Japan) supported on a $1 \mathrm{~mm}$-mesh window screen (Baermann funnel). The Baermann funnels were incubated at $25^{\circ} \mathrm{C}$ for $72 \mathrm{~h}$, after being filled with water to the top of the funnel. The extracted nematodes were counted using a microscope.

\section{Field experiments:}

Field experiments were conducted in 2011 in a field of T sukuba Research Institute of Katakura Chikkarin Co., Ltd., Ibaraki, Japan, which was naturally infested with $M$. hapla and $M$. incognita. No fumigants or contact nematicides had been applied in the field since 2009. The properties of the soil were: andosol, $30 \%$ sand, $40 \%$ silt, $30 \%$ clay; LiC, pH $\left(\mathrm{H}_{2} \mathrm{O}\right) 5.8$, total $\mathrm{C}=24.0 \mathrm{~g} / \mathrm{kg}$ soil, total $\mathrm{N}=3.3 \mathrm{~g} / \mathrm{kg}$ soil. The field was divided into 12 plots (each $3 \times 3 \mathrm{~m}$ ). Nematode densities at transplanting were assessed using a composite soil sample collected from six sites of each plot. 
The initial populations of RKNs were measured by the Baermann method and the real-time PCR method as described above. A fter basal fertilization ( $\mathrm{N}-\mathrm{P}_{2} \mathrm{O}_{5}-\mathrm{K}_{2} \mathrm{O}=20$ 20-20 kg/10 a), the plot soil was mixed well with a shovel. The plots were mulched with a protective plastic cover to reduce evaporation, soil erosion and weeds. Eight 1-monthold eggplants, Solanum melongena L': senryou 2', were transplanted into each plot (total number of plants $=96$ ) and cultivated in 2011 for about 3 months from May 31 to A ugust 24 without irrigation and pesticide application. The yield was determined by weighing all the eggplant's commercial size fruits. A fter cultivation, eggplant roots were carefully dug out from soil with a shovel, and carefully washed to remove the attaching soil completely. The gall index of roots was assessed per plant using Zeck's scale of 0 to 10 (0: no knots on roots, 10: all roots severely knotted or no root system) $(n=96)$ (Zeck, 1971). However, this scale is based on the galls caused by only $M$. incognita, $M$. arenaria, or M. javanica, but not by M. hapla.

\section{Statistical analysis:}

Statistical analysis was performed using the software Excel Statistics 2002 (Social Survey Research Information Co., Ltd., Tokyo, Japan).

\section{RESULTS}

\section{Primer specificity:}

The sequences in the position of $\mathrm{Mh}$ forward primer are different between $M$. incognita and $M$. hapla, while the sequences of $M$. incognita in the position of RKN primers are similar to those of $M$. hapla (T able 1 ). Thus, the newly designed primers $\mathrm{Mh}$ for $\mathrm{M}$. hapla did not amply DNA from $M$. incognita, while primers RKN for $M$. incognita amplified DNA from $M$. hapla at an efficiency of as low as 15\% (date not shown).

Preparation of the calibration curve:

When the andosol in Tokyo was inoculated with RKN $\mathrm{J} 2$ at densities of 5 to 500 individuals $/ 20 \mathrm{~g}$ of soil, highly significant correlations $\left(r^{2}=0.8857, P<0.05\right.$ in $M$. indognita and $r^{2}=0.9978, P<0.01$ in $M$. hapla) were observed between the Ct values and the number of RKN J2 inoculated into the soils (Fig. 1).

A nalysis of relationship between the initial population of M eloidogynespp. and yield of eggplant:

In the Baermann method, both $M$. hapla and $M$. incognita were counted as RKNs since it was impossible to distinguish the species with microscopic observation. The number of RKNs ranged from 0 to $24 \mathrm{~J} 2 / 20 \mathrm{~g}$ soil. In the real-time PCR method, the numbers of $M$. incognita and $M$. hapla were separately measured using the calibration curves obtained in Fig. 1 and ranged from 0.6 to $713 \mathrm{~J} 2$ equivalent (2 2eq)/20 g soil and from 0 to $115 \mathrm{~J} 2 \mathrm{eq} / 20 \mathrm{~g}$ soil, respectively. There was a significant correlation in the number of RKNs between the Baermann and the real-time $P C R$ method $(P<0.001)$, although their absolute values were 26 times different (Fig. 2). There was one site in which RKNs were not detected in the Baermann method, but present at densities of $56 \mathrm{M}$. incognita J2eq/20 g soil and $17 \mathrm{M}$. hapla J2eq/20 g soil with the real-time PCR method.
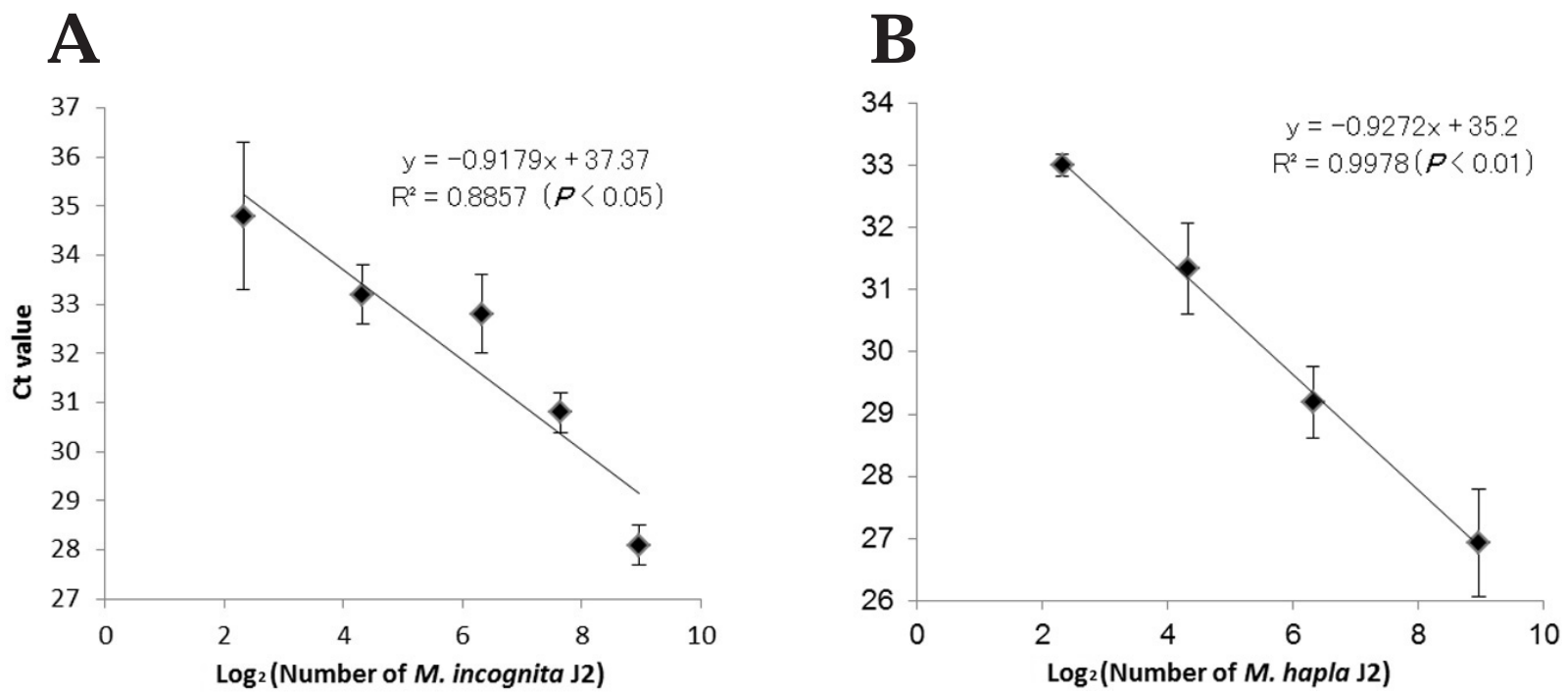

Fig. 1. Relationship between the $C t$ value and the number of M eloidogyne incognita J2s $(A)(P<0.05)$ or $M$. hapla $\mathrm{J} 2 \mathrm{~s}(\mathrm{~B})$ inoculated in andosol $(\mathrm{P}<0.01)$. 


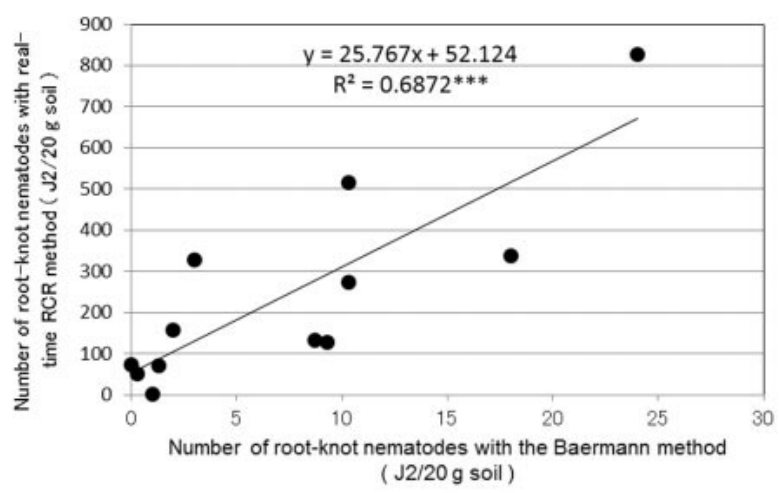

Fig. 2. Relationship between the number of root-knot nematodes (M eloidogyne incognita and $M$. hapla) in andosol with the Baermann method and the sum of $M$. incognita and $M$. hapla with the real-time $P C R$ method $(P<0.001)$.

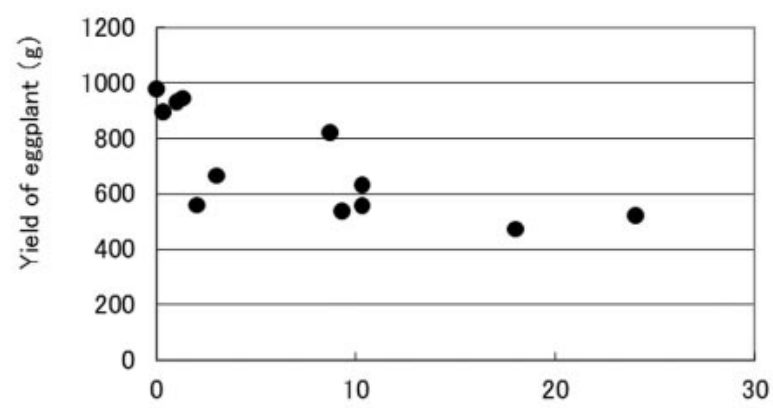

Initial population of root-knot nematodes ( $2 / 20 \mathrm{~g}$ soil)

Fig. 3. Relationship between the yields of eggplant and the initial population of root-knot nematodes (M eloidogyne incognita and $M$. hapla) in andosol with the Baermann method.
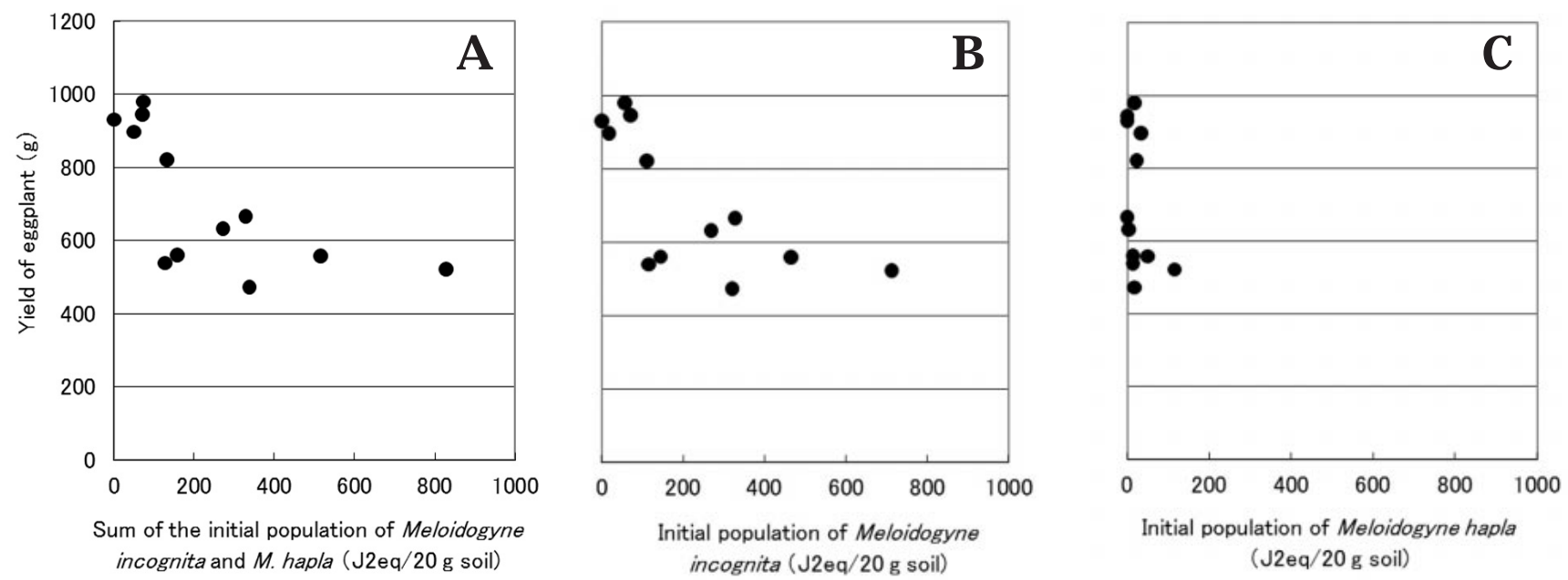

Fig. 4. Relationship between the yields of eggplant and the initial population of sum of M eloidogyne incognita and M. hapla (A), M. incognita (B), and $M$. hapla $(C)$ in andosol with the real-time PCR method.

There was a significant correlation between the initial population of RKNs with the Baermann method at transplanting and the yield ( $P=0.007$ ) ( $F$ ig. 3). The yield decreased in the plots with an initial population of RKNs more than $2 \mathrm{~J} 2 / 20 \mathrm{~g}$ soil.

In the case of real-time PCR, yield decreased in plots with the sum of initial $M$. incognita and $M$. hapla more than $128 \mathrm{~J} 2 \mathrm{eq} / 20 \mathrm{~g}$ soil (Fig. 4A ). Based on the initial populations of $\mathrm{M}$. incognita, yield losses were observed in plots containing over $115 \mathrm{~J} 2 \mathrm{eq} / 20 \mathrm{~g}$ soil (Fig. 4B). In contrast, there was no significant correlation between the yield and the initial population of $M$. hapla $(P=0.2)$ ( $F$ ig. $4 C$ ).

In the present study, galls were observed on all the eggplant roots in all the plots and the gall index ranged 1 to 7 . It tended to increase with the initial populations of RKNs with the Baermann method, the sum of $M$. incognita and $M$. hapla and of $M$. incognita with the real-time PCR method,

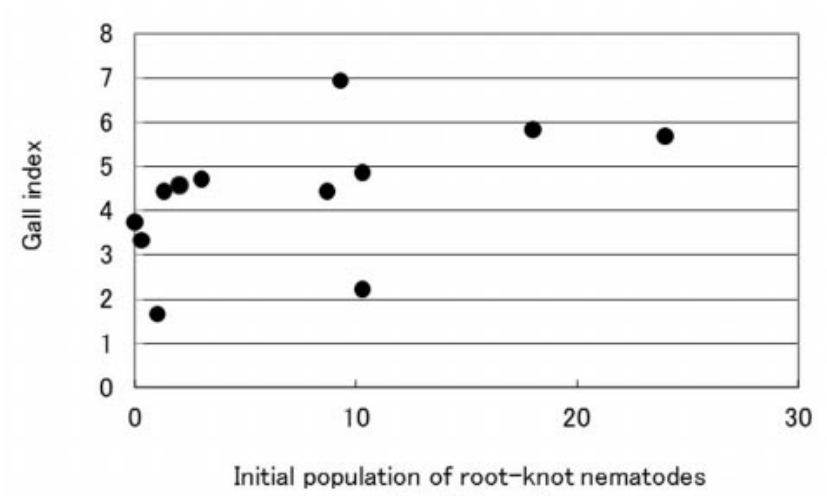

(J2/20 g soil)

Fig. 5. Relationship between the gall indices and the initial population of root-knot nematodes (M eloydogyne incognita and $M$. hapla) in andosol with the Baermann method. 

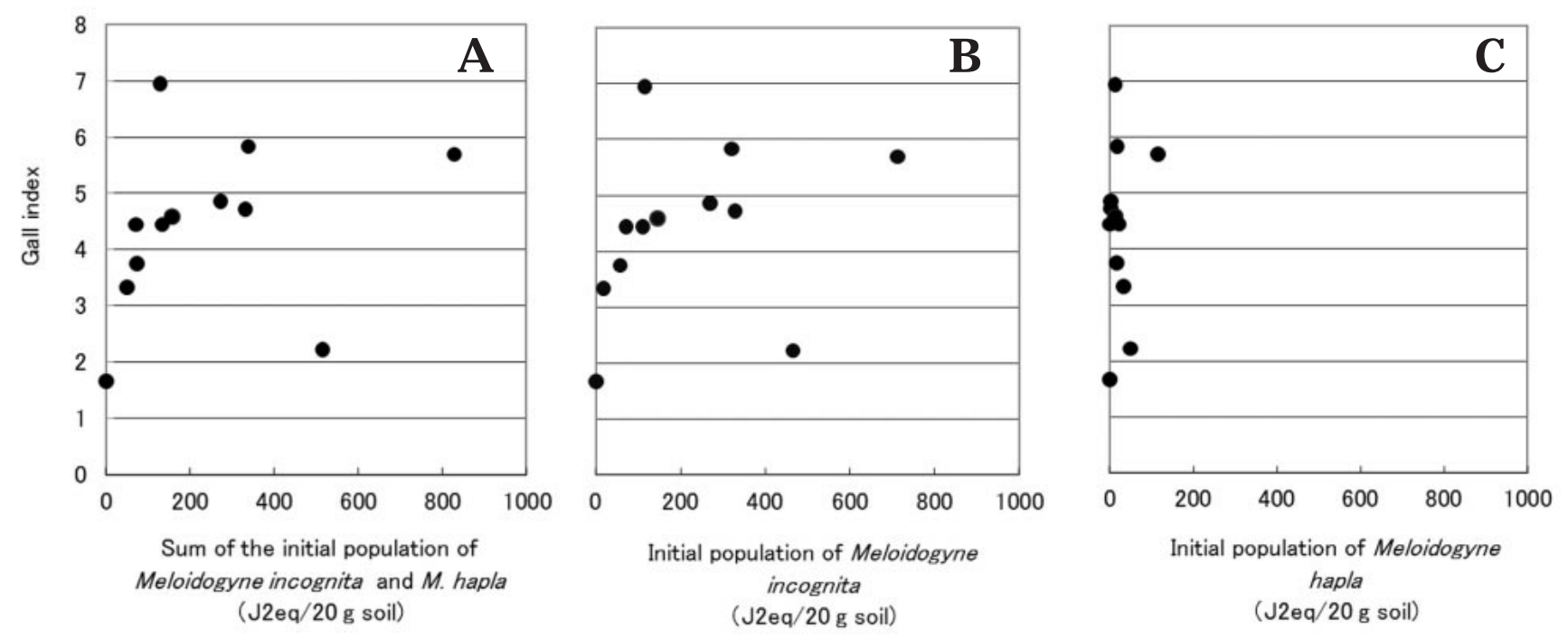

Fig. 6. Relationship between the gall indices and the initial population of sum of M eloidogyne incognita and M . hapla (A), M . incognita (B), and M . hapla (C) in andosol with the real-time PCR method.

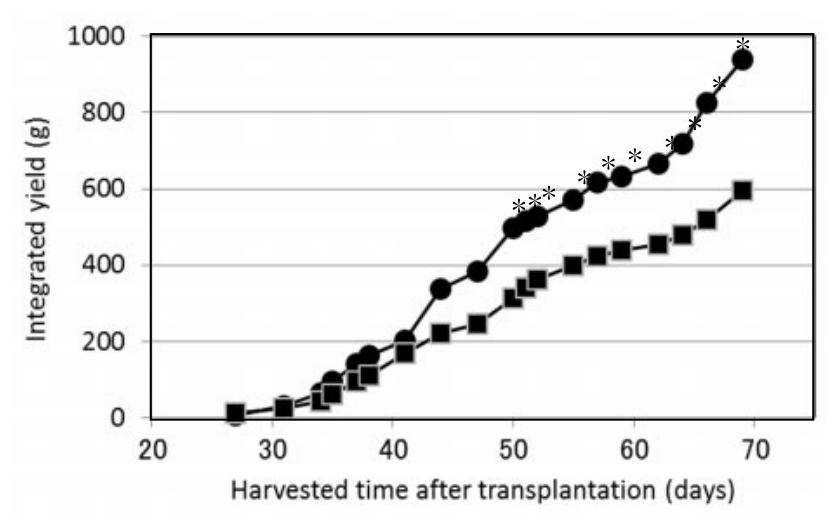

Fig. 7. Effect of the initial density of root-knot nematodes (RKNs) with the Baermann method on cumulative yields of eggplants in the plots.

: 0 to $2 / 20 \mathrm{~g}$ soil of the initial density of RKNs, $\boldsymbol{\square}$ : more than $2 / 20 \mathrm{~g}$ soil of the initial density of RKNs. A sterisks indicate a significant difference between the two treatments by Student's t-test $(P<0.05)$.

although there were no significant correlations between them $(P=0.09$ in Fig. $5, P=0.42$ in Fig. $6 A, P=0.40$ in Fig. $6 B)$. In contrast, there were no such relations between the gall index and the initial populations of $M$. hapla $(P=0.6)$ (Fig. 6C).

Periodical change in eggplant yield:

T welve plots were separated into two groups based on the initial densities of RKNs (0-2 and >2 J2/20 g soil) and periodical changes in the yields were calculated. There were no marked differences in the yield pattern in the initial period between the two groups, but significant differences became obvious 50 days after transplanting $(P<0.05)$ (Fig. 7).

\section{DISCUSSION}

Knowledge of the relationship between preplant plantparasitic nematode population densities in soil and plant growth is essential for the prediction of yield losses caused by nematodes and for choosing the best management practices. This study developed the real-time PCR primers $\mathrm{M} \mathrm{h}$ and RKN which sensitively quantified $M$. hapla and $M$. incognita, respectively, in andosol (Fig. 1). This method is advantageous in determining nematode densities, as our previous study already reported (Min et al., 2012). In the field test, RKNs were detected with real-time PCR in the soil which RKNs were not detected with the Baermann method (Fig. 2). This kind of result was in agreement with the previous study (Min et al., 2012). These results further support the merits of the real-time PCR method, especially in enumerating the densities of nematodes not easily detected with the Baermann method, such as dormant or quiescent nematode forms. However, there could be some technical errors in the density estimated with the real-time PCR method, because the andosol used for preparing the calibration curves was different from the andosol used for the field study. Goto et al. (2010) reported that the Ct values of soils with the same density of the target nematode were not the same among three kinds of andosols, although the difference among the single soil type, andosol, was much smaller than that between two different soil types (andosol and sandy soil). In addition, the density of $M$. incognita might be overestimated. The primer set RKN amplifies DNA even from $M$. hapla at an efficiency of $15 \%$, as this defect was already reported in a previous paper (T oyota et al., 2008), indicating that 100 individuals of $\mathrm{M}$. hapla are detected as 
15 individual of $M$. incognita. For example, in a field containing 100 individuals of $\mathrm{M}$. hapla and 15 individual of $\mathrm{M}$. incognita, the density of $M$. incognita is estimated as 30 individuals of $M$. incognita, two times higher than the actual density. Therefore, caution is needed when quantifying $M$. incognita in fields infested with a large population of $M$. hapla. However, the density of $M$. incognita was much higher than that of $\mathrm{M}$. hapla in the field used in this study and therefore, the false detection of $M$. hapla as a small population of $M$. incognita should not be a serious problem, since M. incognita would be estimated as 101.5 in a field containing 100 individuals of $M$. incognita and 10 individuals of $M$. hapla. In fields with mixed populations of $M$. incognita and $M$. hapla, the quantification of $M$. hapla using the primer set $\mathrm{Mh}$ is essential, since the primer set does not amplify DNA from $M$. incognita at all, enabling the quantification of only M. hapla.

Y ield losses were observed in plots with an initial population of RKNs more than $2 \mathrm{~J} 2 / 20 \mathrm{~g}$ soil measured with the Baermann method. This level is quite similar to that in a previous study in which the economic threshold level for eggplant was estimated at $1 \mathrm{~J} 2 / 20 \mathrm{~g}$ soil of $\mathrm{M}$. incognita (Schomaker and Been, 2006). In contrast, the yield in carrot decreased in fields with 20 to $30 \mathrm{~J} 2 / 20 \mathrm{~g}$ soil of $\mathrm{M}$. incognita at seeding time (Sano, 1988). In US, the damage threshold density in carrot estimated in a two-year study on $\mathrm{M}$. hapla was 3.0 to 14 eggs $/ 20 \mathrm{ml}$ in organic soil and 12 to 38 eggs/20 ml in mineral soil (Gugino et al., 2006). The yield loss in spinach was observed in soils with more than 40 eggs and J2s of M. incognita/20 ml soil (Di V ito et al., 2004). Also, the economic threshold level in burdock, cucumber and tomato was $1.6 \mathrm{~J} 2 / 20 \mathrm{~g}$ soil (Plant protection station, 2011; Y amada, 1992). Vovlas et al. (2005 and 2008) estimated the tolerance limits to $M$. javanica and $M$. incognita in potato and celery as 10 to 13 and 3 for eggs and $\mathrm{Js} / 20 \mathrm{ml}$ soil, respectively. Collectively, the yield loss level of this study in eggplant was comparable to that in burdock, celery, cucumber and tomato, and markedly lower than that in carrot and spinach. While carrot and spinach were cultivated for two months in the previous studies, eggplant and the other vegetables were cultivated for over four months. The length of the cultivation period might cause different yield loss levels. Indeed, there were no differences in the yields in the initial period between the plots having different initial populations of RKNs, but significant differences became obvious 50 days after transplanting $(\mathrm{P}<0.05)$ (Fig. 7). This result suggests that crops with shorter cultivation periods might show higher tolerance levels to RKNs.

In the case of real-time PCR, the yield decreased in the plots with more than $128 \mathrm{~J} 2 \mathrm{eq} / 20 \mathrm{~g}$ soil of $\mathrm{M}$. incognita and
M. hapla or $115 \mathrm{~J} 2$ eq/20 g soil of M. incognita (Fig. 4A , B). These yield loss levels were much higher than the level obtained with the Baermann method. A similar result is reported in a combination of radish and $\mathrm{P}$. penetrans; the economic threshold level was less than 1 individual $/ 20 \mathrm{~g}$ soil with the Baermann method, while $5 \mathrm{~J} 2 \mathrm{eq} / 20 \mathrm{~g}$ soil with the real-time PCR method (Sato et al., 2010). This may be due to the real-time PCR method detecting eggs and dormant forms of nematodes that are not detected with the Baermann method.

The gall index tended to increase with the initial population of M. incognita, when the gall index was estimated with the Zeck's scale which measures galls caused by $M$. incognita, M . arenaria, and M . javanica. The gall size is different between $M$. incognita and $M$. hapla, and the former makes relatively larger galls on lateral roots (Hunt and Handoo, 2009). Thus, relatively larger galls formed by $M$. incognita might have made it difficult to see smaller galls of M. hapla, and therefore galls caused by $M$. hapla might be underestimated in this study.

In conclusion, we developed a rapid quantification method using real-time PCR for $M$. incognita and $M$. hapla in an andosol and evaluated the relationship between the initial population of M eloidogyne spp. and the yield of eggplant in an andosol.

\section{LITERATURE CITED}

A tkins, S. D., Manzanilla-Lopez, R. H., Franco, J., Peteira, B. and Kerry, B. R. (2005) A molecular diagnostic method for detecting Nacobbus in soil and in potato tubers. Nematology 7, 193-202.

Berry, S., Fargette, M ., Morand, S. and Cadet, P. (2007) Reliability of PCR-based techniques for detection and discrimination of plant-parasitic nematodes of sugarcane. Nematology 9, 499-514.

Berry, S. D., Fargette, M., Spaull, V. W., M orand, S. and Cadet, P. (2008) Detection and quantification of rootknot nematode (M eloidogyne javanica), lesion nematode (Pratylenchus zeae) and dagger nematode (Xiphinema elongatum) parasites of sugarcane using real-time PCR. Molecular and Cellular Probes 22, 168-176.

Blok, V. C. and Powers, T. O. (2009) Biochemical and molecular identification. In: Root-Knot Nematodes (Perry, R. N., M oens, M. and Starr, J. L. eds.), CA BI, W allingford 98-118.

Den Nijs, L. and Van Den Berg, W. (2013) The added value of proficiency tests: choosing the proper method for extracting M eloidogyne second-stage juveniles from soil. Nematology 15, 143-151.

Di Vito, M., Vovlas, N. and Castillo, P. (2004) Host-parasite 
relationships of M eloidogyne incognita on spinach. Plant Pathology 53, 508-514.

Goto, K., Sato, E. and Toyota, K. (2009) A novel detection method for the soybean cyst nematode Heterodera glycines using soil compaction and real-time PCR. Nematological Research 39, 1-7.

Goto, K., Sato, E., Gang, L. F., T oyota, K. and Sugito, T. (2010) Comparison of calibration curves prepared by soil compaction and ball milling methods for direct quantification of the potato cyst nematode Globodera rostochiensis in soil. Nematological Research 40, 41-45.

Gugino, B. K., A bawi, G. S. and Ludwig, J. W. (2006) Damage and management of M eloidogyne hapla using oxamyl on carrot in New Y ork. Journal of Nematology 38, 483-490.

Hagiya, S. (1992) Plant parasitic nematodes in Kanto district. In: Senchu kenkyu no ayumi (Nakasono, K. ed.), Syowado, Saga, 306-309. (in Japanese)

Hunt, D. J. and Handoo, Z. A . (2009) T axonomy, identification and principal species. In: Root-K not Nematodes (Perry, R. N., M oens, M. and Starr, J. L. eds.), CA BI, Wallingford, 55-97.

Ichinohe, M. (1992) Historical review of nematological researches in Japan. In: Senchu kenkyu no ayumi (Nakasono, K. ed.), Syowado, Saga, 3-9. (in Japanese)

Ingham, R. E. (1994) Nematodes. In: Methods of soil analysis. Part 2. Microbiological and biochemical properties (W eaver, R. W. ed.) Madison, WI, USA, A merican Society of A gronomy, 459-490.

Iwahori, H., Sano, Z. and Ogawa, T. (2000) Distribution of main plant-parasitic nematodes in sweet potato and taro fields in Kyushu and Okinawa, Japan. 1. Survey in the central and southern parts in Kyushu Island (Kumamoto, M iyazaki and Kagoshima Prefs.) and development of an effective DNA analysis method for species identification. Kyushu Plant Protection Research 46, 112-117. (in Japanese with English summary).

Leal, I., Green, M ., A llen, E., Humble, L. and Rott, M. (2007) A pplication of real-time PCR method for the detection of pine wood nematode, Burusaphelenchus xylophilus, in wood samples from lodgepole pine. Nematology 9 , 351-362.

M cSorley, R. and Frederick, J. J. (2004) Effect of extraction method on perceived composition of the soil nematode community. A pplied Soil E cology 27, 55-63.

Madani, M., Subbotin, S. A . and Moens, M. (2005) Quantitative detection of the potato cyst nematode, Globodera pallida, and the beet cyst nematode, Heterodera schachtii, using Real-T ime PCR with SYBR green I dye. Molecular and Cellular Probes 19, 81-86.

Min, Y. Y ., T oyota, K ., Goto, K., Sato, E., M izuguchi, S., A be N., Nakano, A and Sawada, E. (2011) Development of a direct quantitative detection method for M eloidogyne incognita in sandy soils and its application to sweet potato cultivated fields in Tokushima prefecture, Japan. Nematology 13, 95-102.

M in, Y. Y ., T oyota, K. and Sato, E. (2012) A novel nematode diagnostic method using the direct quantification of major plant-parasitic nematodes in soil by real-time PCR. Nematology 14, 265-276.

Moens, M., Perry, R. N. and Starr, J. L. (2009) M eloidogyne species - a diverse group of novel and important plant parasites. In: Root-K not Nematodes (Perry, R. N., Moens, M. and Starr, J. L. eds.), CA BI, Wallingford, 117.

Oka, Y., Koltai, H., Bar-Eyal, M., M or, M., Sharon, E., Chet, I. and Spiegel, Y. (2000) New strategies for the control of plant-parasitic nematodes. Pest M anagement Science 56, 983-988.

Oka, Y. and Mizukubo, T. (2008) T omato culture filtrate stimulates hatching and activity of M eloidogyne incognita juveniles. Nematology 11, 51-61.

Plant protection station (2011) Todofuken ga setteisiteiru yobojosuijun (yasai). http://www.jppn.ne.jp/jpp/bouteq /bojosuijun_data/yasai.pdf (in Japanese)

Sano, Z. (1988) Relation between population density of M eloidogyne incognita and yield of carrot plant in summer plantings. Proceeding of the Association for Plant Protection of Kyushu 34, 127-130. (in Japanese)

Sato, E., M in, Y. Y., Shirakashi, T ., W ada, S., and T oyota, K (2007) Detection of root-lesion nematode, Pratylenchus penetrans (Cobb), in a nematode community using realtime PCR. Japanese Journal of Nematology 37, 87-92.

Sato, E., Goto, K., M in, Y. Y ., Shirakashi, T ., T oyota, K and Suzuki, C. (2010) Quantitative detection of Pratylenchus penetrans from soil by using soil compaction and realtime PCR. Japanese Journal of Nematology 40, 1-6.

Schomaker, C. H. and Been, T. H. (2006) Plant growth and population dynamics. In: Plant Nematology (Perry, R. $\mathrm{N}$. and M oens, M. eds.), CA BI, W allingford, 275-301.

T akakura, S. (1984) Spread and increase in population of the plant parasitic nematodes in some field converted from paddy fields. A nnual Report of the Society of Plant Protection of North Japan 35, 176-179. (in Japanese)

T oyota, K., Shirakashi, T ., Sato, E., Wada, S. and M in, Y. Y. (2008) Development of a real-time PCR method for the potato-cyst nematode Globodera rostochiensis and the root-knot nematode M eloidogyne incognita. Soil Science 
and Plant Nutrition 54, 72-76.

Vovlas, N., Mifsud, D., Landa, B. B. and Castillo, P. (2005) Pathogenicity of the root-knot nematode M eloidogyne javanica on potato. Plant Pathology 54, 657-664.

Vovlas, N., Lucarelli, G., Sasanelli, N., T roccoli, A., Papajova, I., Palomares-Rius, J. E . and Castillo, P. (2008) Pathogenicity and host-parasite relationships of the root-knot nematode M eloidogyne incognita on celery. Plant Pathology 57, 981-987.

Yamada, E. (1992) Plant parasitic nematodes in Hokkaido district. In: Senchu kenkyu no ayumi (Nakasono, K ed.), Syowado, Saga, 297-300. (in Japanese)

Y an, G., Smiley, R. W . and Okubara, P. A . (2012) Detection and quantification of Pratylenchus thornei in DNA extracted from soil using real-time PCR. Phytopathology 102, 14-22.

Zeck, W. M. (1971) A rating scheme for field evaluation of root-knot nematode infestations. PflanzenschutzNachrichten 24, 141-144.

Received : 7 F ebruary, 2013 